\title{
Hamiltonian-T*- Laceability in Jump Graphs Of Diameter Two
}

\author{
Manjunath. $G^{1}$ Murali. ${ }^{2}$ \\ ${ }^{I}$ Department of Mathematics, Gopalan college of Engineering and Management, Bangalore. \\ ${ }^{2}$ Department of Mathematics, Dr.Ambedkar Institute of Technology, Bangalore
}

\begin{abstract}
Let $G$ be the nonempty graph. The Jump graph $J[G]$ of $G$ is the graph whose vertices are edges of $G$, and where two vertices of $J[G]$ are adjecent if and only if they are not adjacent in $G$, equivalently, the Jump graph $J[G]$ is the complément of line graph L[G]. In [2] the authors have obtained Hamiltonian Jump graphs. In this paper we charecterised Hamiltonian laceability of Jump graph and also explore the Laceability in jump graph of Star, Friendship and Ladder graphs.
\end{abstract}

Keywords : Connected Graph, Jump graph, Friendship graph, Ladder graph,Hamiltonian-t*-laceable Graph.

\section{Introduction}

Let $\mathrm{G}$ be a finite, simple, connected and undirected graph. Let $\mathrm{u}$ and $\mathrm{v}$ be two vertices in $\mathrm{G}$. The distance between $u$ and $v$ denoted by $d(u, v)$ is the length of a shortest $u-v$ path in $G$. G is Hamiltonian laceable if there exists a Hamiltonian path between every pair of vertices in $G$ at an odd distance. G is Hamiltonian-tlaceable (Hamiltonian-t*-laceable) if there exists a Hamiltonian path between every pair (at least one pair) of vertices $\mathrm{u}$ and $\mathrm{v}$ in $\mathrm{G}$ with the property $\mathrm{d}(\mathrm{u}, \mathrm{v})=\mathrm{t}, 1 \leq \mathrm{t} \leq$ diamG.

The Line graph $\mathrm{L}[\mathrm{G}]$ of $\mathrm{G}$ has the edges of $\mathrm{G}$ as its vertices and two vertices of $\mathrm{L}[\mathrm{G}]$ are adjacent if and only if they are adjacent in G. The complement of the line graph $\mathrm{L}[\mathrm{G}]$ is called the Jump graph J[G] of G. That is, the Jump graph $J[G]$ is the graph defined on $E[G]$ and in which two vertices are adjacent if and only if they are not adjacent in $\mathrm{G}$.

In [3], [4] and [5], the authors have studied Hamiltonian-t-laceability and Hamiltonian-t*-laceability of various graph structures. In this paper we explore the Hamiltonian-t*-laceablity properties of the Jump graph $\mathrm{J}[\mathrm{G}]$ of the Star graph, the Friendship graph and the Ladder graphs.

\section{Definition 1:}

The Jump graph $\mathbf{J}[\mathrm{G}]$ of a graph $\mathrm{G}$ is a graph defined on $\mathrm{E}[\mathrm{G}]$ and in which two vertices is adjacent if and only if they are not adjacent in G.

\section{Definition 2:}

A Graph is called a Friendship graph if every pair of its nodes has exactly one common neighbor. This condition is called the friendship condition. Furthermore, a graph is called a windmill graph, if it consists of $\mathrm{k} \geq 1$ tringles, which have a unique common node, known as the "politician". Clearly, any windmill graph is a friendship graph

The Friend ship Graph (or Dutch Windmill graph or n-Fan graph) $F_{n}$ is a planar undirected graph with $2 n+1$ vertices and $3 n$ edges.

\section{Definition 3:}

The Ladder graph $L_{n}$ is a planar undirected graph with $2 n$ vertices and $n+2(n-1)$ edges.

Figures 1, 2 and 3 below illustrate the Jump Graph of the Star $\mathbf{K}_{\mathbf{1}, \mathbf{5}}$, the Friendship graph $\mathbf{F}_{\mathbf{2}}$ and the Ladder Graph $\mathbf{L}_{3}$ respectively.

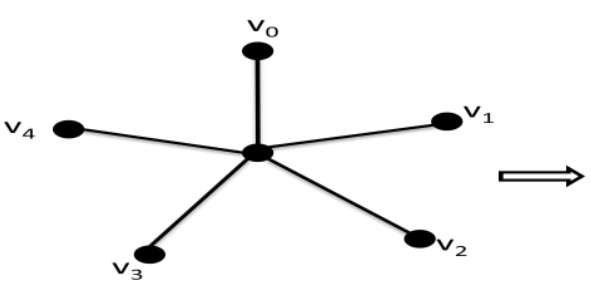

Fig.1:

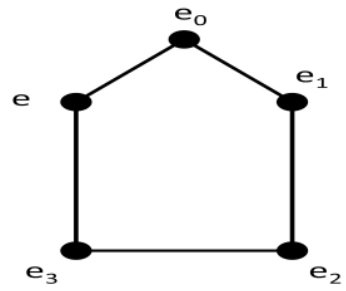

$\mathbf{L}\left[\mathbf{K}_{1,5}\right]$

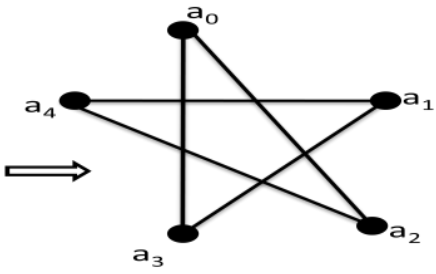

$\mathbf{J}\left[\mathbf{K}_{1,5}\right]$ 


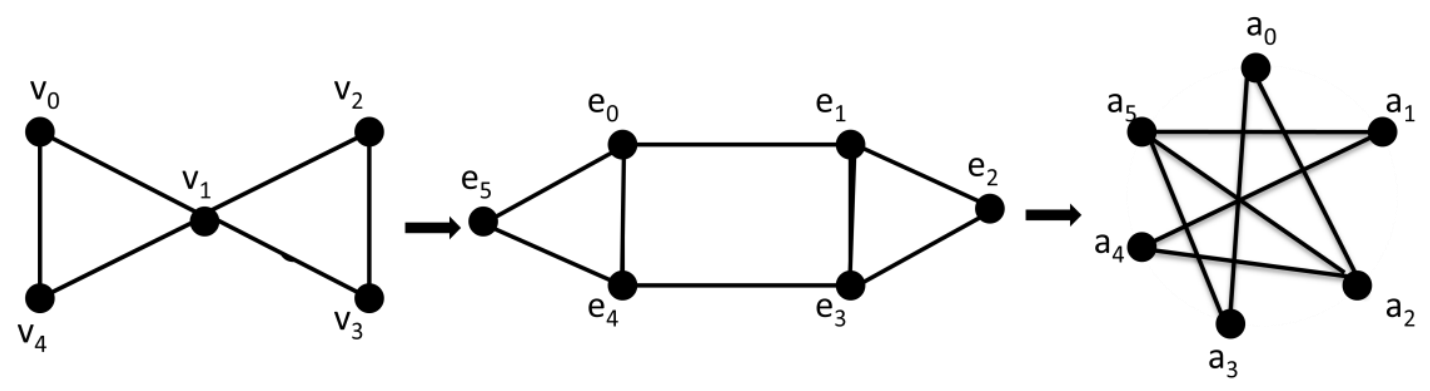

Fig.2: $\quad \mathbf{F}_{2}$

$\mathbf{L}\left[\mathbf{F}_{2}\right]$

$\mathbf{J}\left[\mathbf{F}_{2}\right]$

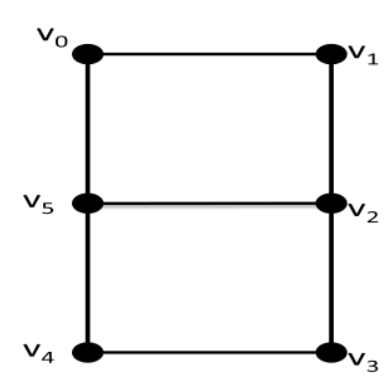

Fig.3: $\quad \mathbf{L}_{3}$

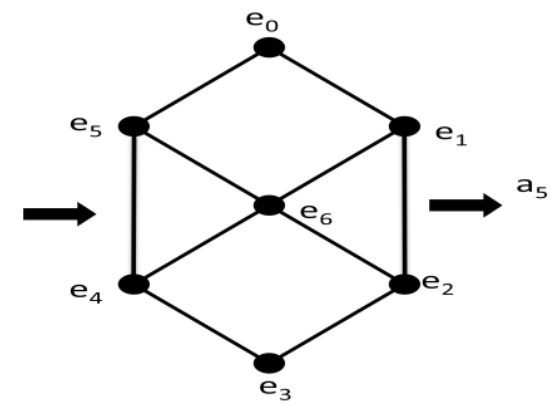

$\mathbf{L}\left[\mathbf{L}_{3}\right]$

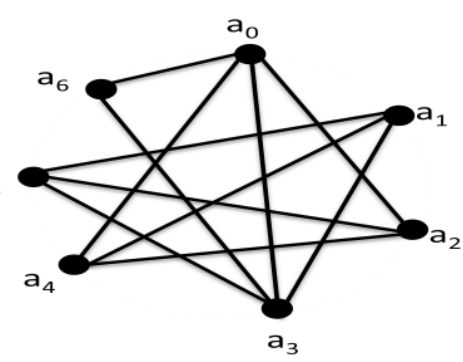

$\mathbf{J}\left[\mathbf{L}_{3}\right]$

II. Results

Theorem 1: The Jump Graph $J[G]$ of the star Graph $G=K_{1, n}$ us Hamiltonian- $t$-laceable for $1 \leq t \leq d i a m G$; $n \geq 6$.

Proof: Consider Jump Graph J[G], which is a complement of Line graph of G, denote the vertices of J[G] by $a_{0}-a_{1}-a_{2}------, a_{n-1}, a_{0}=a_{n}$ under modulo $\mathrm{n}$.

Now we have the following cases

Case 1: For $\mathrm{t}=1$

Sub case 1: If $\mathrm{n}$ is even

In J[G] $d\left(a_{1}, a_{3}\right)=1$ and the path $P:\left(a_{1}, a_{5}\right) \cup\left(a_{5}, a_{n-1}\right) \cup\left(a_{n-1}, a_{n-3}\right) \cup\left(a_{n-3}, a_{n-5}\right) \cup---\cup$ $\left(a_{7}, a_{2}\right) \cup\left(a_{2}, a_{n-2}\right) \cup\left(a_{n-2}, a_{n-4}\right) \cup\left(a_{n-4}, a_{n-6}\right) \cup----\cup\left(a_{6}, a_{4}\right) \cup\left(a_{4}, a_{0}\right) \cup\left(a_{0}, a_{3}\right) \quad$ is $\quad$ a Hamiltonian path from $a_{1}$ to $a_{3}$.

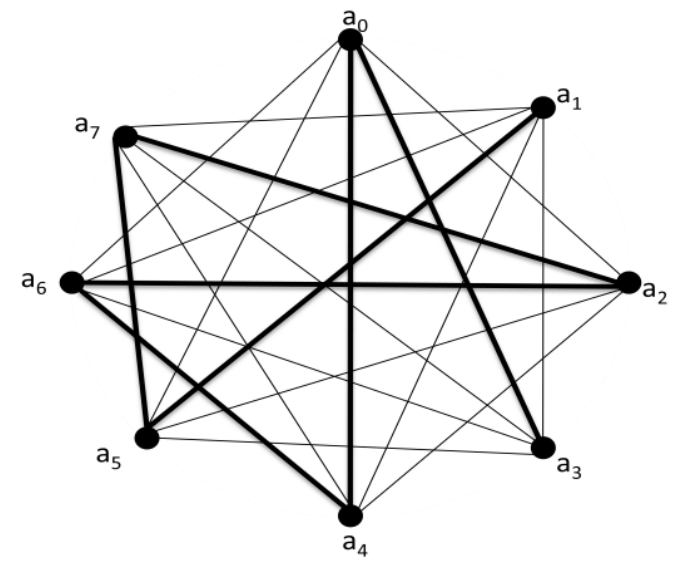

Fig.4: Hamiltonian path from the vertex $a_{1}$ to $a_{3}$ in Jump Graph $\mathbf{J}\left[\mathbf{K}_{1,8}\right]$ Sub case 2: If $n$ is odd $(n \neq 7)$ 
In J[G] $d\left(a_{1}, a_{3}\right)=1$ and the path $P:\left(a_{1}, a_{5}\right) \cup\left(a_{5}, a_{n-2}\right) \cup\left(a_{n-2}, a_{n-4}\right) \cup\left(a_{n-4}, a_{n-6}\right) \cup--$ $--\cup\left(a_{7}, a_{2}\right) \cup\left(a_{2}, a_{n-1}\right) \cup\left(a_{n-1}, a_{n-3}\right) \cup\left(a_{n-3}, a_{n-5}\right) \cup---\cup\left(a_{6}, a_{4}\right) \cup\left(a_{4}, a_{0}\right) \cup\left(a_{0}, a_{3}\right) \quad$ is a Hamiltonian path.

Sub case 3 : If $\mathrm{n}$ is odd $(\mathrm{n}=7)$

In $\mathrm{J}[\mathrm{G}] \quad d\left(a_{1}, a_{3}\right)=1$ and the path $P:\left(a_{1}, a_{5}\right) \cup\left(a_{5}, a_{2}\right) \cup\left(a_{2}, a_{6}\right) \cup\left(a_{6}, a_{4}\right) \cup\left(a_{0}, a_{3}\right)$ is a Hamiltonian path

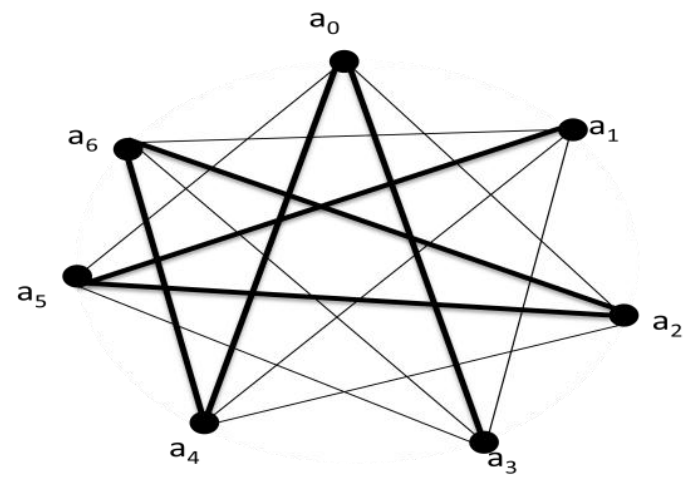

Fig.5: Hamiltonian Path from the vertex $a_{1}$ to $a_{3}$ in Jump Graph $\mathbf{J}\left[\mathbf{K}_{1,7}\right]$

\section{Case 2: For $\mathrm{t}=\mathbf{2}=\operatorname{diam} \mathrm{J}[\mathrm{G}]$}

Sub case 1: If $\mathrm{n}$ is even

In J[G] $d\left(a_{1}, a_{0}\right)=2$ and the path $P:\left(a_{1}, a_{n-2}\right) \cup\left(a_{n-2}, a_{n-4}\right) \cup\left(a_{n-4}, a_{n-6}\right) \cup-----\cup\left(a_{4}, a_{2}\right)$ $\cup\left(a_{2}, a_{n-1}\right) \cup\left(a_{n-1}, a_{n-3}\right) \cup\left(a_{n-3}, a_{n-5}\right) \cup---\cup\left(a_{5}, a_{3}\right) \cup\left(a_{3}, a_{0}\right)$ is a Hamiltonian path from $a_{1}$ to $a_{3}$.

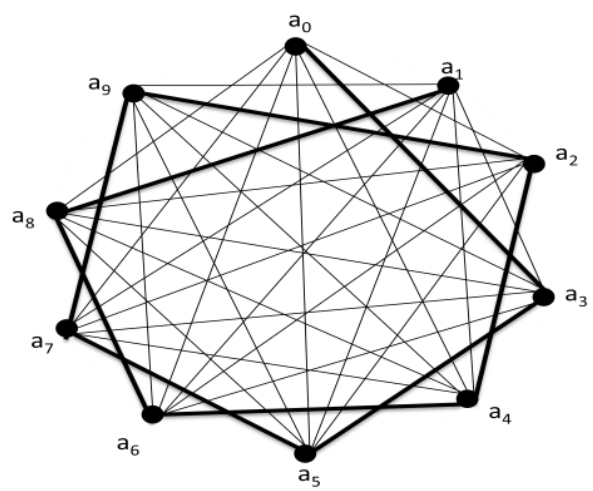

Fig.6: Hamiltonian Path from the vertex $a_{1}$ to $a_{3}$ in Jump Graph $\mathbf{J}\left[\mathbf{K}_{\mathbf{1 , 1 0}}\right]$

Sub case 2: If $\mathrm{n}$ is odd

In $\mathrm{J}[\mathrm{G}] \quad d\left(a_{1}, a_{0}\right)=2$ and the path

$P:\left(a_{1}, a_{n-1}\right) \cup\left(a_{n-1}, a_{n-3}\right) \cup\left(a_{n-3}, a_{n-5}\right) \cup\left(a_{n-5}, a_{n-7}\right) \cup---\cup$

$\left(a_{4}, a_{2}\right) \cup\left(a_{2}, a_{n-2}\right) \cup\left(a_{n-2}, a_{n-4}\right) \cup\left(a_{n-4}, a_{n-6}\right) \cup---\cup\left(a_{5}, a_{3}\right) \cup\left(a_{3}, a_{0}\right)$

is a Hamiltonian path from $a_{1}$ to $a_{3}$. Therefore $\mathrm{G}$ is a Hamiltonian-t*-laceable for $\mathrm{t}=2$. 


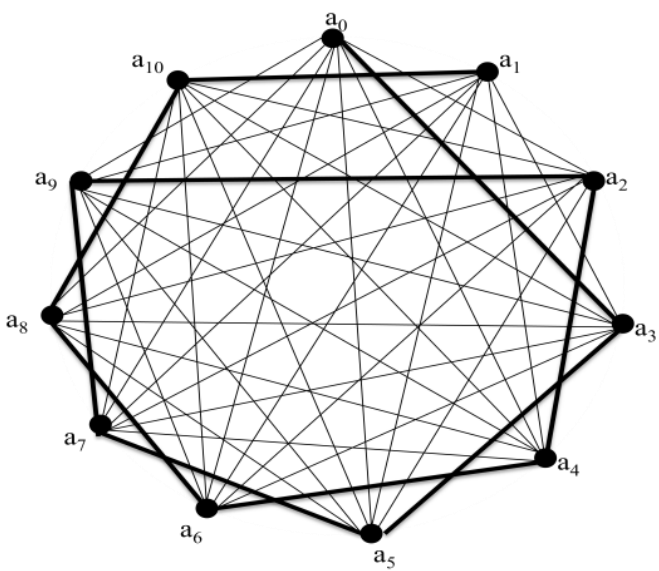

Fig.7: Hamiltonian Path from the vertex $a_{1}$ to $a_{3}$ in Jump Graph $\mathbf{J}\left[\mathbf{K}_{1,11}\right]$

\section{Remarks:}

1. If $1 \leq \mathrm{n} \leq 4, \mathrm{~J}[\mathrm{G}]$ is either trivial or disconnected graph.

2. If $\mathrm{n}=5$, then in $\mathrm{J}[\mathrm{G}]$, we consider the following cases

For $\mathrm{t}=1$ and in $d\left(a_{1}, a_{3}\right)=1$ then the path $P:\left(a_{1}, a_{4}\right) \cup\left(a_{4}, a_{2}\right) \cup\left(a_{2}, a_{0}\right) \cup\left(a_{0}, a_{3}\right)$

is a Hamiltonian path.

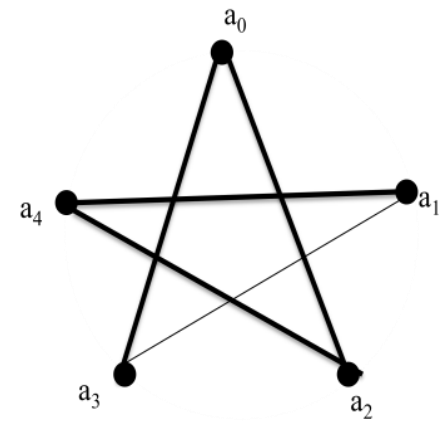

Fig.8. Hamiltonian path from the vertex $a_{1}$ to $a_{3}$ in Jump Graph $\mathbf{J}\left[\mathbf{K}_{1,5}\right]$

For $\mathrm{t}=2$, Hamiltonian Path does not exists.

Theorem 2: The Jump Graph $J[G]$ where $G=F_{n}, n \geq 2$, the Friendship Graph is Hamiltonian-t*-laceable for $1 \leq t \leq \operatorname{diam} G$.

Proof: Consider Jump Graph J [G], which is a complement of Line graph of G, denote the vertices of J[G] by $a_{0}-a_{1}-a_{2}------, a_{n-1}, a_{0}=a_{n}$.

Case 1: For $\mathrm{t}=1$

Sub case 1: If $\mathrm{n}$ is even

In J [G] $d\left(a_{1}, a_{4}\right)=1$ and the path $P:\left(a_{1}, a_{9}\right) \cup\left(a_{9}, a_{7}\right) \cup\left(a_{7}, a_{11}\right) \cup---\cup\left(a_{n+17}, a_{n+19}\right) \cup---$ $---\cup\left(a_{21}, a_{23}\right) \cup\left(a_{23}, a_{19}\right) \cup\left(a_{19}, a_{15}\right) \cup\left(a_{15}, a_{17}\right) \cup\left(a_{17}, a_{13}\right) \cup\left(a_{13}, a_{5}\right) \cup\left(a_{5}, a_{3}\right) \cup$ $\left(a_{3}, a_{10}\right) \cup$

$\left(a_{10}, a_{12}\right) \cup\left(a_{12}, a_{14}\right) \cup\left(a_{14}, a_{6}\right) \cup\left(a_{6}, a_{16}\right) \cup\left(a_{16}, a_{22}\right) \cup---\cup\left(a_{n+14}, a_{n+16}\right) \cup---\cup$ $\left(a_{18}, a_{n+18}\right)$

$\cup\left(a_{n+18}, a_{20}\right) \cup\left(a_{20}, a_{8}\right) \cup\left(a_{8}, a_{2}\right) \cup\left(a_{2}, a_{0}\right) \cup\left(a_{0}, a_{4}\right)$ is a Hamiltonian path.

Hence $\mathrm{J}[\mathrm{G}]$ is Hamiltonian- $\mathrm{t} *$-laceable for $\mathrm{t}=1$. 


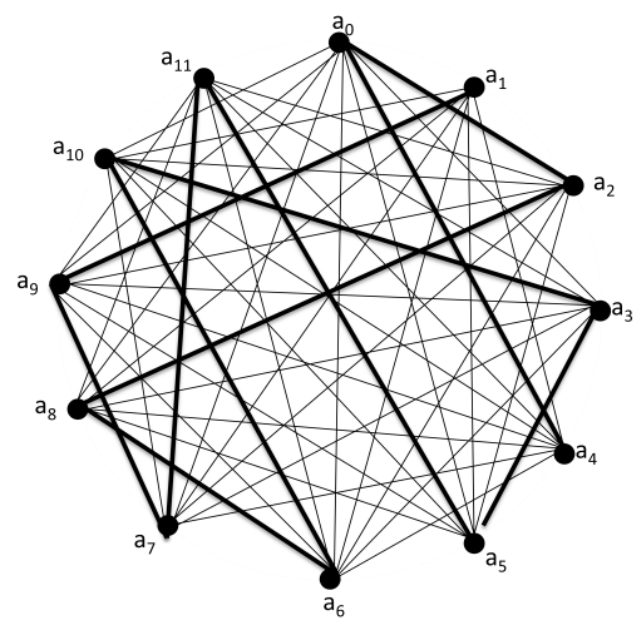

Fig.8. Hamiltonian path from the vertex $a_{1}$ to $a_{4}$ in Jump Graph $\mathbf{J}\left[\mathbf{F}_{4}\right]$

Sub case 2: If $\mathrm{n}$ is odd

In J [G] $d\left(a_{1}, a_{4}\right)=1$ and the path $P:\left(a_{1}, a_{5}\right) \cup\left(a_{5}, a_{3}\right) \cup-----\cup\left(a_{3 n-1}, a_{2 n+6}\right) \cup\left(a_{2 n+6}, a_{2 n+4}\right)$

$\cup---\cup\left(a_{20}, a_{18}\right) \cup\left(a_{18}, a_{16}\right) \cup\left(a_{16}, a_{14}\right) \cup\left(a_{14}, a_{12}\right) \cup\left(a_{12}, a_{10}\right) \cup\left(a_{10}, a_{6}\right) \cup\left(a_{6}, a_{8}\right) \cup$

$\left(a_{8}, a_{0}\right) \cup$

$----\left(a_{3 n-2}, a_{2 n+5}\right) \cup\left(a_{2 n+5}, a_{2 n+3}\right) \cup\left(a_{2 n+3}, a_{19}\right) \cup\left(a_{19}, a_{17}\right) \cup\left(a_{17}, a_{15}\right) \cup\left(a_{15}, a_{13}\right) \cup\left(a_{13}, a_{9}\right)$

$\cup\left(a_{9}, a_{11}\right) \cup\left(a_{11}, a_{21}\right) \cup\left(a_{21}, a_{7}\right) \cup\left(a_{7}, a_{4}\right)$ is a Hamiltonian path. Hence $\mathrm{J}\left[\mathrm{F}_{\mathrm{n}}\right]$ is a Hamiltonian- $\mathrm{t}^{*}$ laceable for $\mathrm{t}=1$.

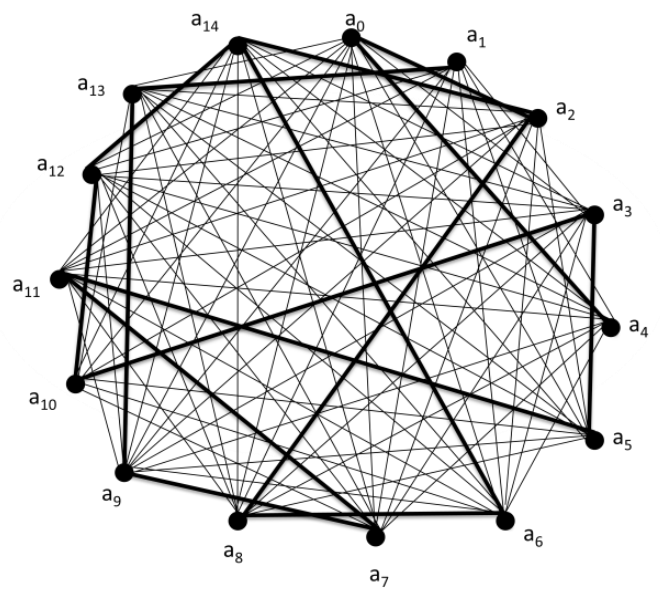

Fig.9. Hamiltonian path from the vertex $a_{1}$ to $a_{4}$ in Jump Graph $\mathbf{J}\left[\mathbf{F}_{5}\right]$

Case 2: For $\mathrm{t}=2$

Sub case 1: If $\mathrm{n}$ is even

In $\mathrm{J} \quad[\mathrm{G}] \quad d\left(a_{1}, a_{2}\right)=2$ and the path $P:\left(a_{1}, a_{5}\right) \cup\left(a_{5}, a_{3}\right) \cup\left(a_{3}, a_{11}\right) \cup----\cup\left(a_{2 n+1}, a_{19}\right)$

$\cup\left(a_{19}, a_{17}\right) \cup\left(a_{17}, a_{15}\right) \cup\left(a_{15}, a_{13}\right) \cup\left(a_{13}, a_{9}\right) \cup\left(a_{9}, a_{7}\right) \cup\left(a_{7}, a_{4}\right) \cup\left(a_{4}, a_{8}\right) \cup\left(a_{8}, a_{6}\right) \cup$

$\left(a_{6}, a_{10}\right)$

$\cup\left(a_{10}, a_{14}\right) \cup\left(a_{14}, a_{12}\right) \cup\left(a_{12}, a_{16}\right) \cup----\cup\left(a_{2 n}, a_{18}\right) \cup----\cup\left(a_{2 n+6}, a_{2 n+4}\right) \cup\left(a_{2 n+4}, a_{22}\right) \cup$

$\left(a_{22}, a_{0}\right) \cup\left(a_{0}, a_{2}\right)$ is a Hamiltonian path. Hence $\mathrm{J}\left[\mathrm{F}_{\mathrm{n}}\right]$ is a Hamiltonian- $\mathrm{t}$-laceable for $\mathrm{t}=2$ 


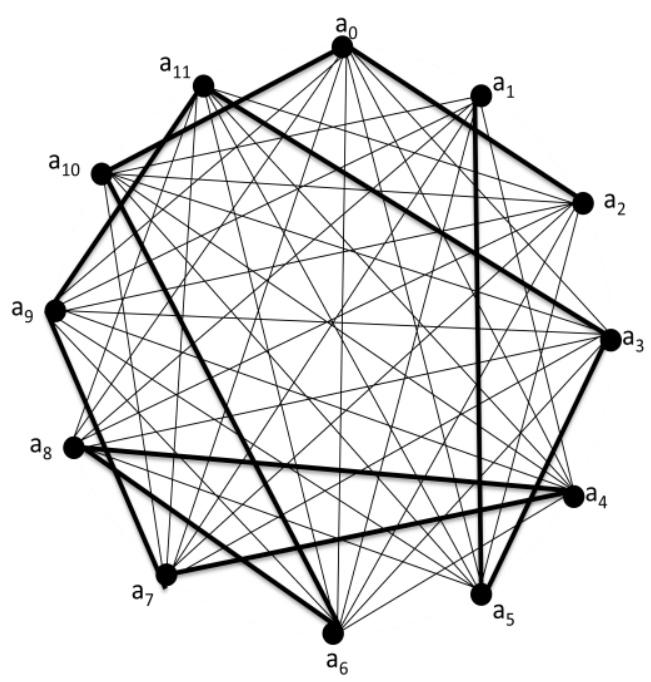

Fig.10: Hamiltonian path from the vertex $a_{1}$ to $a_{2}$ in Jump Graph $\mathbf{J}\left[\mathbf{F}_{4}\right]$

Case (ii): If $\mathrm{n}$ is odd

In J [G] $d\left(a_{1}, a_{2}\right)=2$ and the path $P:\left(a_{1}, a_{5}\right) \cup\left(a_{5}, a_{3}\right) \cup\left(a_{2 n+7}, a_{2 n+5}\right) \cup\left(a_{2 n+5}, a_{2 n+3}\right)$

$\cup\left(a_{2 n+3}, a_{2 n+2}\right) \cup--$

$------\left(a_{19}, a_{17}\right) \cup\left(a_{17}, a_{15}\right) \cup\left(a_{15}, a_{13}\right) \cup\left(a_{13}, a_{9}\right) \cup\left(a_{9}, a_{11}\right) \cup\left(a_{11}, a_{7}\right)$

$\cup\left(a_{4}, a_{8}\right) \cup\left(a_{8}, a_{6}\right) \cup\left(a_{6}, a_{10}\right) \cup$

$\left(a_{10}, a_{14}\right) \cup\left(a_{14}, a_{12}\right) \cup\left(a_{12}, a_{16}\right) \cup----\cup\left(a_{2 n+3}, a_{20}\right) \cup\left(a_{20}, a_{18}\right)$

$\cup---\cup\left(a_{2 n+6}, a_{2 n+8}\right) \cup-----\left(a_{0}, a_{2}\right)$ is Hamiltonian path. Hence $\mathrm{J}\left[\mathrm{F}_{\mathrm{n}}\right]$ is a Hamiltonian- $\mathrm{t}$ *-laceable for $\mathrm{t}=2$.

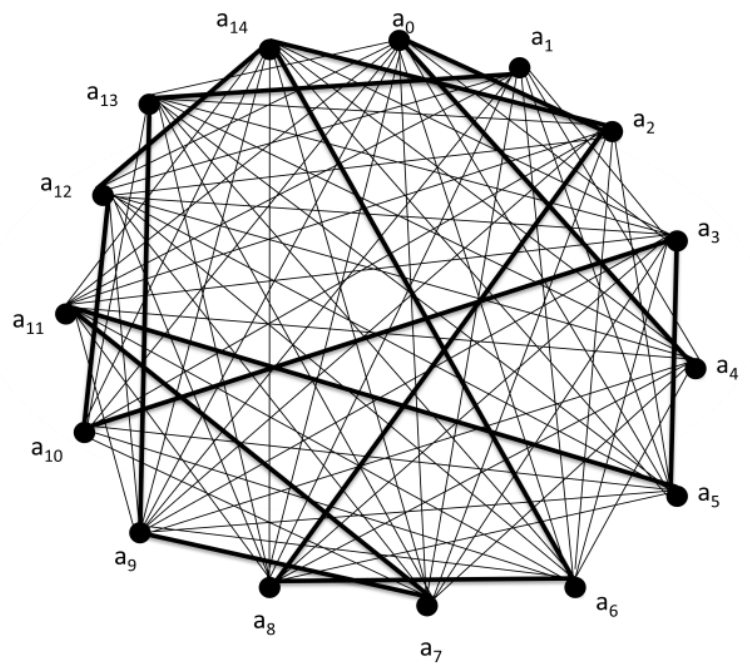

Fig.10: Hamiltonian path from the vertex $a_{1}$ to $a_{2}$ in Jump Graph $\mathbf{J}\left[\mathbf{F}_{5}\right]$

Theorem3: The Jump Graph $J[G]$ where $G=L_{n}, n \geq 3$, the Ladder graph is Hamiltonian-t*-laceable for $1 \leq t \leq \operatorname{diam} G$.

Proof: Consider Jump Graph J [G], which is a complement of Line graph of G, denote the vertices of J[G] by $a_{0}-a_{1}-a_{2}------, a_{n-1}, a_{0}=a_{n}$.

Now we have the following cases

Case 1: For $\mathrm{t}=1$

Sub case 1: If $n$ is even 
In $\mathrm{J} \quad[\mathrm{G}] d\left(a_{1}, a_{3}\right)=1$ and the path $P:\left(a_{1}, a_{5}\right) \cup\left(a_{5}, a_{7}\right) \cup\left(a_{7}, a_{3 n-3}\right) \cup---\cup\left(a_{21}, a_{19}\right) \cup$ $\left(a_{19}, a_{17}\right) \cup\left(a_{17}, a_{15}\right) \cup\left(a_{15}, a_{13}\right) \cup\left(a_{13}, a_{11}\right) \cup\left(a_{11}, a_{9}\right) \cup\left(a_{9}, a_{3 n-4}\right) \cup---\cup$

$\left(a_{20}, a_{18}\right) \cup\left(a_{18}, a_{16}\right) \cup$

$\left(a_{16}, a_{14}\right) \cup\left(a_{14}, a_{12}\right) \cup\left(a_{12}, a_{8}\right) \cup\left(a_{8}, a_{10}\right) \cup\left(a_{10}, a_{4}\right) \cup\left(a_{4}, a_{6}\right) \cup\left(a_{6}, a_{2}\right) \cup\left(a_{2}, a_{0}\right) \cup\left(a_{0}, a_{3}\right)$ is a Hamiltonian path. Hence $\mathrm{J}\left[\mathrm{L}_{\mathrm{n}}\right]$ is a Hamiltonian- $\mathrm{t}^{*}$-laceable for $\mathrm{t}=1$.

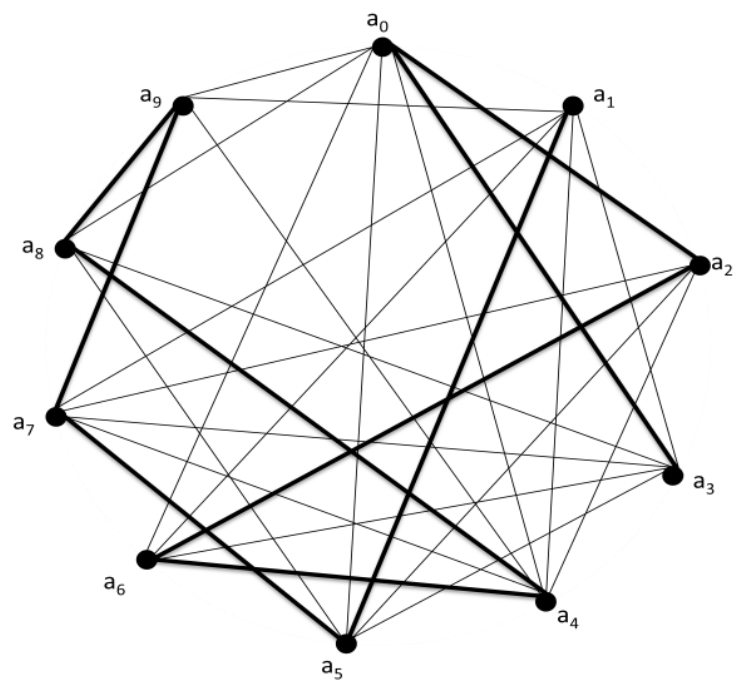

Fig.11: Hamiltonian path from the vertex $a_{1}$ to $a_{3}$ in Jump Graph $\mathbf{J}\left[\mathbf{L}_{\mathbf{4}}\right]$

Sub case 2: If $\mathrm{n}$ is odd

In $\mathrm{J} \quad[\mathrm{G}] \quad d\left(a_{1}, a_{3}\right)=1$ and the path $P:\left(a_{1}, a_{5}\right) \cup\left(a_{3 n-4}, a_{3 n-6}\right) \cup---\cup\left(a_{19}, a_{17}\right) \cup\left(a_{17}, a_{15}\right)$

$\cup\left(a_{15}, a_{13}\right) \cup\left(a_{13}, a_{11}\right) \cup\left(a_{11}, a_{9}\right) \cup\left(a_{9}, a_{7}\right) \cup\left(a_{7}, a_{2}\right) \cup\left(a_{2}, a_{12}\right) \cup\left(a_{12}, a_{10}\right) \cup\left(a_{10}, a_{6}\right)$

$\cup\left(a_{6}, a_{8}\right)$

$\cup---\cup\left(a_{n-3}, a_{16}\right) \cup\left(a_{16}, a_{14}\right) \cup\left(a_{14}, a_{18}\right) \cup\left(a_{18}, a_{4}\right) \cup\left(a_{4}, a_{0}\right) \cup\left(a_{0}, a_{3}\right)$ is a Hamiltonian path.

Hence $\mathrm{J}\left[\mathrm{L}_{\mathrm{n}}\right]$ is a Hamiltonian- $\mathrm{t} *$-laceable for $\mathrm{t}=1$

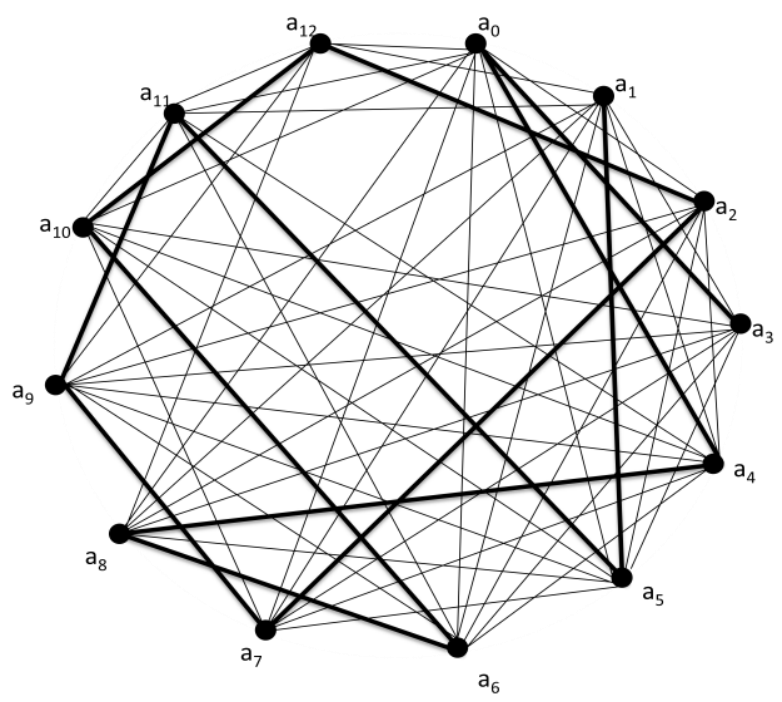

Fig.12: Hamiltonian path from the vertex $a_{1}$ to $a_{3}$ in Jump Graph $\mathbf{J}\left[\mathbf{L}_{\mathbf{5}}\right]$

Case 2: For $\mathrm{t}=2$

Sub case 1: If $n$ is even 
In $\quad$ J $\quad d\left(a_{1}, a_{2}\right)=2 \quad$ and the path

$P:\left(a_{1}, a_{4}\right) \cup\left(a_{4}, a_{0}\right) \cup\left(a_{0}, a_{6}\right) \cup\left(a_{6}, a_{3}\right) \cup\left(a_{3}, a_{7}\right) \cup\left(a_{7}, a_{13}\right) \cup$

$\left(a_{13}, a_{15}\right) \cup\left(a_{3 n-3}, a_{3 n-5}\right) \cup---\cup$

$\left(a_{14}, a_{118}\right) \cup\left(\left(a_{118)}, a_{186}\right)\right) \cup\left(-a_{8}, a_{5}\right)\left(\left(a_{3} a_{54}, a_{23}\right)_{-6}\right) \cup---\cup\left(a_{12}, a_{14}\right) \cup$

is a Hamiltonian path. Hence $\mathrm{J}\left[\mathrm{L}_{\mathrm{n}}\right]$ is a Hamiltonian- $\mathrm{t} *$-laceable for $\mathrm{t}=2$

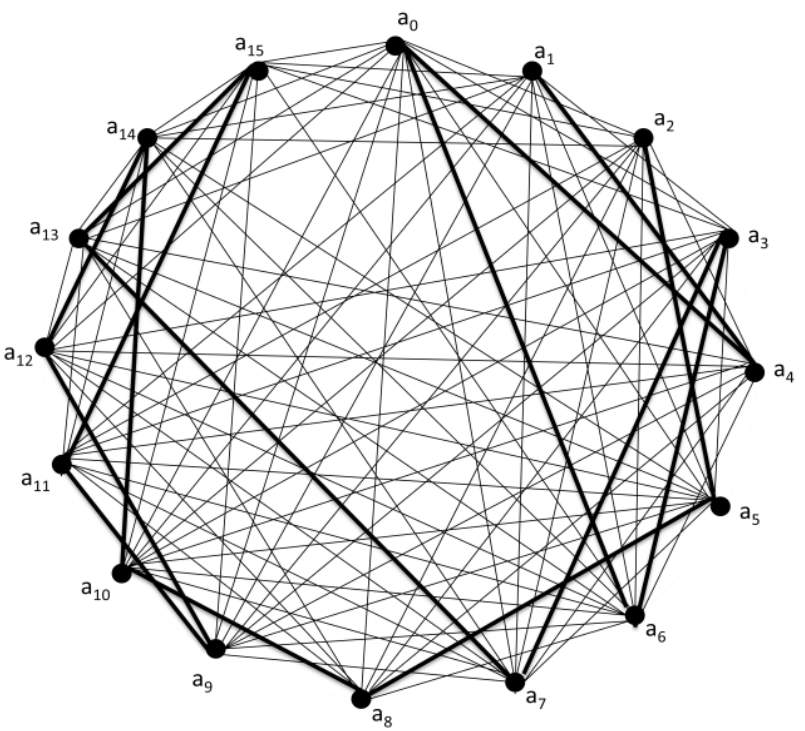

Fig.13: Hamiltonian path from the vertex $a_{1}$ to $a_{2}$ in Jump Graph $\mathbf{J}\left[\mathbf{L}_{6}\right]$

Sub case 2: If $\mathrm{n}$ is odd

In J [G] $d\left(a_{1}, a_{2}\right)=2$ and the path $P:\left(a_{1}, a_{4}\right) \cup\left(a_{4}, a_{0}\right) \cup\left(a_{0}, a_{6}\right) \cup\left(a_{6}, a_{8}\right) \cup\left(a_{8}, a_{12}\right) \cup\left(a_{12}, a_{10}\right)$ $\cup----\cup\left(a_{3 n-3}, a_{3 n-5}\right) \cup---\cup\left(a_{18}, a_{14}\right) \cup\left(a_{14}, a_{16}\right) \cup\left(a_{16}, a_{3}\right) \cup\left(a_{3}, a_{7}\right) \cup\left(a_{7}, a_{9}\right) \cup$ $\left(a_{9}, a_{11}\right) \cup$

$\left(a_{11}, a_{13}\right) \cup\left(a_{13}, a_{15}\right) \cup\left(a_{15}, a_{17}\right) \cup\left(a_{17}, a_{3 n-4}\right) \cup\left(a_{3 n-4}, a_{3 n-6}\right) \cup\left(a_{19}, a_{5}\right) \cup\left(a_{5}, a_{2}\right)$ is a Hamiltonian path. Hence $\mathrm{J}\left[\mathrm{L}_{\mathrm{n}}\right]$ is a Hamiltonian- $\mathrm{t} *$-laceable for $\mathrm{t}=2$

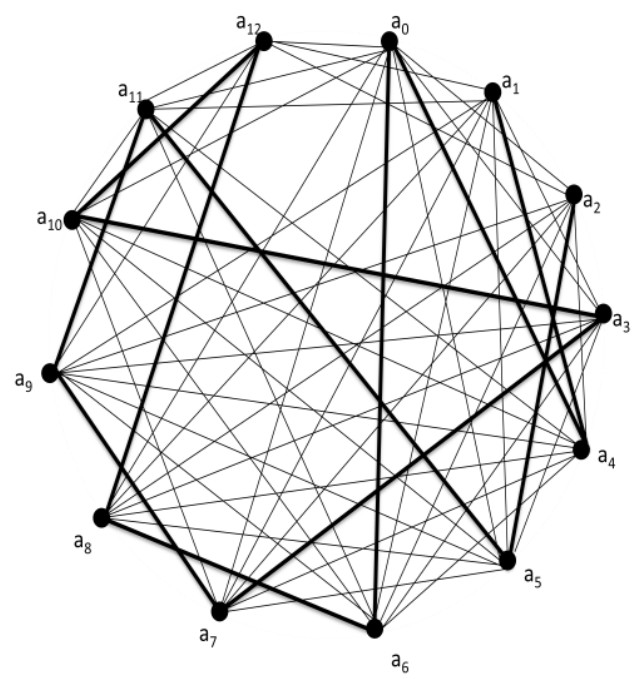

Fig.14: Hamiltonian path from the vertex $a_{1}$ to $a_{2}$ in Jump Graph $\mathbf{J}\left[\mathbf{L}_{5}\right]$ 


\section{References}

[1]. G.Chartrand, H.Hevia, E.B.M. Schultz, Sub graph distance graphs defined byEdge transfers,

[2]. Bayindureng $\quad$ Wu, Jixiang Meng, Hamiltonian Jump graphs, Discrete mathematics 289(2004)95-106.

[3]. Girisha.A and R.Murali, Hamiltonian laceability in a class of 4-Regular Graphs, IOSR Journal of Mathematics, Volume 4, Issue 1 (Nov.- Dec. 2012), pp 07-12.

[4]. G.Manjunath, R.Murali and S.K.Rajendra, Hamiltonian Laceability in the Modified Brick Product of Odd Cycles, International Journal of Graph Theory, submitted.

[5]. G.Manjunath and R.Murali, Hamiltonian Laceability in the Brick Product $\mathrm{C}(2 \mathrm{n}+1,1, \mathrm{r})$ Publish research paper in International Journal of Graph Theory(GBS Publishers), submitted. 